\title{
RESEARCH TO INDUSTRY AND INDUSTRY TO RESEARCH
}

\section{GAS EMISSION MONITORING: A GROWING CHALLENGE FOR MSW INCINERATORS}

In the era of bustling industrial activity and growing number of industrial plants, regulation and continuous monitoring of emissions have become increasingly important.

Despite emissions monitoring being a standard and fairly straightforward process for all industrial plants, it is of utmost importance: it protects the nature and human beings proactively and ensures the safety of us all. What is more, by effective process optimization we can save a lot of valuable resources.

This is particularly true for MSW incineration plants where the perception of human health risk is particularly sensible and consequently the public attention is very high.

What makes emissions monitoring challenging is the changing operational environment where regulations, standards and processes can change. As the operational environment changes, the emission limits and allowed gas concentrations change consequently. This, in turn, requires continuous adaptability and capability to reassess the procedures and technologies by the emissions monitoring stakeholders.

Besides, emission monitoring is important for research activity because it allows to evaluate the results of process optimization on a full scale or to define the emission factors for environmental or human impact evaluations. This represents a relevant case in which industrial equipment is necessary for improving research of environmental engineering applied to air pollution control.

An interesting chance to fulfill this growing challenge of emissions monitoring is the use of FTIR (Fourier Transform Infrared) gas analyzer technology. FTIR is one of the most reliable and effective technologies out there for emissions monitoring. It is the most powerful technology for simultaneous measurements of multiple gases and the industry standard in many emissions monitoring applications. What is more, its flexibility and versatility make it a very cost-effective and multipurpose tool for measurements of a wide range of gas components in various industrial processes requiring continuous emissions monitoring.

\section{How ftir technology works}

FTIR stands for Fourier Transform Infrared spectroscopy. It is a powerful gas measurement technology for simultaneous measurements of multiple gases. The ability to detect and measure almost any gas, combined with the robustness and reliability of the technology, makes FTIR ideal for a wide variety of applications.
Nearly all molecules can be identified by their characteristic absorption spectrum as each molecule absorbs infrared radiation at its characteristic frequencies. Every molecular structure has a unique combination of atoms, which produces a unique spectrum when exposed to infrared light. The only exceptions are noble gases and diatomic elements such as $\mathrm{O}_{2}$, which do not absorb IR light. IR absorption spectrum can be thought of as a fingerprint unique to each molecule.

The infrared spectrum is a plot of infrared radiation related quantities as a function of wavelength or wavenumber. According to Lambert-Beer's law, the absorption strength (peak height) is directly proportional to concentration, and this way the IR spectrum can be used to determine concentrations of gases in the sample.

Two interesting applications that apply FTIR technology are described below (Figure 1):

- Gasmet CEMS Ile is a solution for a broad range of demanding continuous emissions monitoring applications. CEMS Ile has both TÜV and MCERTS certificates according QAL1 EN14181/15267. All parts of the system are heated to $180 \mathrm{C}$ and this extractive system is ideal for measuring pollutants from hot, wet and corrosive gas streams. The solution is typically used (but not limited to this) to simultaneously measure the following 16 gases: $\mathrm{H}_{2} \mathrm{O}, \mathrm{CO}_{2}, \mathrm{CO}, \mathrm{N}_{2} \mathrm{O}, \mathrm{NO}, \mathrm{NO}_{2}, \mathrm{SO}_{2}, \mathrm{HCl}, \mathrm{HF}$, $\mathrm{NH}_{3}, \mathrm{CH}_{4}, \mathrm{C}_{2} \mathrm{H}_{6}, \mathrm{C} 3 \mathrm{H} 8, \mathrm{C}_{2} \mathrm{H}_{4}$ and $\mathrm{CH}_{2} \mathrm{O}$. On top of these, FTIR analyzer can also measure Total Organic Carbon (TOC) and NOx.

- Portable DX4000 measuring system is an ideal "portable" tool for stack testing. In this configuration, just a single analyzer can be easily and quickly used by a single operator to measure almost all criteria pollutants. This gives a great chance to save a lot of time and effort in field, and grant real time reliable gas concentration analysis but also give the option to save all data for storage or post analysis study. According actual European Legislation EN 14793-2017, portable FTIR can also be approved as AM (Alternative Methods) to replace traditional SRM (Standard Reference Methods) and this fact gives to analysis laboratories the option to use FTIR analyzers to perform QAL2 and AST into EN14181 systems periodical quality checks.

\section{Main benefit of ftir technology}

- It is futureproof - Quick changes to measurement ranges and additions to list of measured gases are possible and easily done. New gases and gas ranges 


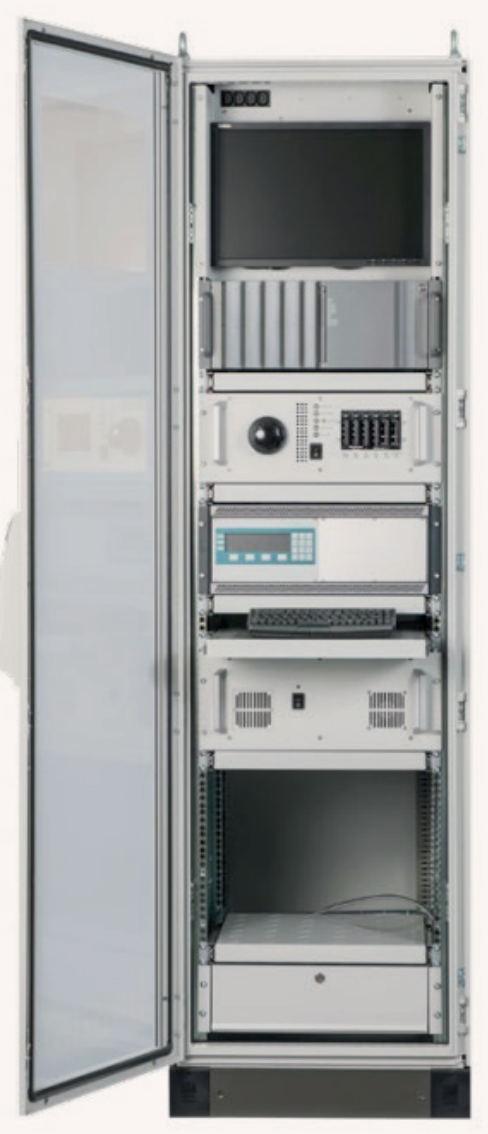

(a)

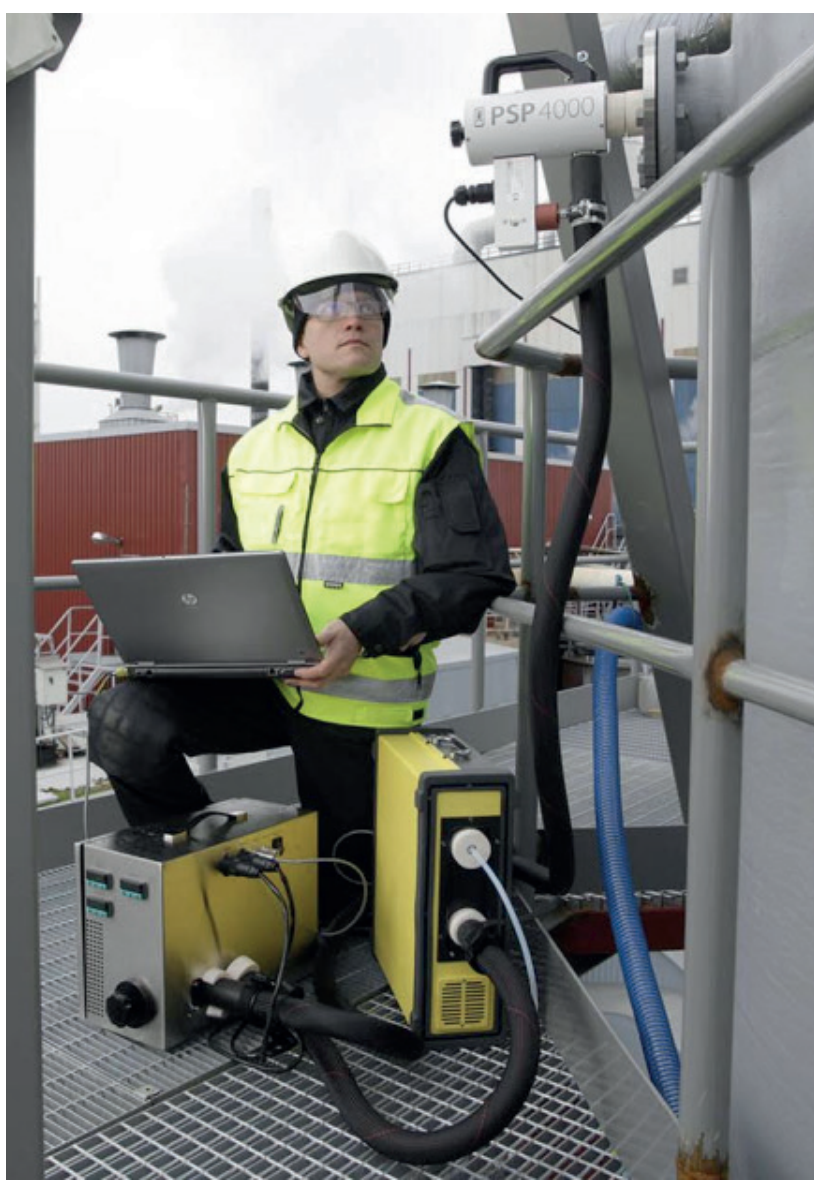

(b)

FIGURE 1: FTIR technology applications: (a) Gasmet CEMS Ile; (b) Portable DX4000 measuring system.

can be added to the analysis at any time without any changes to hardware. This can be done by the users themselves.

- Multicomponent capability - FTIR is the only technology that measures such a wide range of gases simultaneously. All key emissions monitoring compounds such as $\mathrm{NOx}, \mathrm{SO}_{2}$ and $\mathrm{CO}$ can be measured. In case of waste incineration, also $\mathrm{HCl}, \mathrm{HF}$ and TOC are added to the measured gases, and $\mathrm{NH}_{3}$ if SCR or SNCR is used.

- Proven technology - Gasmet FTIR analyzers hold TÜV and MCERTS certificates (QAL1) according EN14181/15267. All Gasmet's FTIR emissions monitoring systems have been certified throughout their history.

- Reliability - FTIR is extremely sensitive, accurate and robust technology. It provides low maintenance cost for the user and long system life-time combined with low uncertainty. Additionally, its high availability provides low downtime for the operators.

- Application flexibility - Of course with FTIR it is possible to supply CEMS (Continous Emissions Monitoring System) suitable for most of industrial applications as i.e. for waste incinerators. But moreover it is possible to have fully portable gas analyzer suitable for stacks testing (quick checks, process research, emergency situations, reliability field tests, quick backup solution, ...).

\section{Example of ftir "library" for cems application}

Gasmet FTIR equipped with CALCMET software is able to detect and quantify up to 50 gas in the same time, of course the software must be equipped with a specific "Iibrary" that includes typical absorption spectra for each gas to be analyzed including all possible cross interference components.

Here following Gasmet experience about CEMS application into incinerators for both stationary and portable applications- a typical library. Of course it can be changed/modified for other gas and ranges at any time (Figure 2).

Gasmet Technologies (www.gasmet.com) is a Finnish high technology company that develops, manufactures and markets FTIR gas analyzers and monitoring systems for a variety of industrial, environmental and safety applications.

Ital Control Meters srl (www.italcontrol.it) is an Italian company with more than 25 years experience as exclusive distributor of high level technologies for process automation and emission control aimed to Italian industries, including Gasmet products.

\section{Gianantonio Favalessa *}

Ital Control Meters S.r.I., via della Valle 67, Carate Brianza, Italy

* email: favalessa@italcontrol.it 


\begin{tabular}{|c|c|c|c|c|c|c|c|}
\hline \multicolumn{8}{|c|}{ EXTENDED CEM APPLICATION GAS-APP-003 } \\
\hline$\#$ & Compound name & Formula & $\begin{array}{c}\text { CAS } \\
\text { number }\end{array}$ & $\begin{array}{l}\text { Minimum } \\
\text { range }\end{array}$ & $\begin{array}{l}\text { Typical } \\
\text { range }\end{array}$ & \begin{tabular}{c|} 
Maximum \\
range
\end{tabular} & Unit \\
\hline 1 & Water & $\mathrm{H}_{2} \mathrm{O}$ & $7732-18-5$ & 25 & 30 & 40 & vol-\% \\
\hline 2 & Carbon dioxide & $\mathrm{CO}_{2}$ & $124-38-9$ & 10 & 20 & 30 & vol-\% \\
\hline 3 & Carbon monoxide & co & $630-08-0$ & 60 & 500 & 10000 & $\mathrm{ppm}$ \\
\hline 4 & Nitrous oxide & $\mathrm{N}_{2} \mathrm{O}$ & $10024-97-2$ & 50 & 100 & 500 & $\mathrm{ppm}$ \\
\hline 5 & Nitrogen monoxide (Nitric oxide) & NO & $10102-43-9$ & 100 & 200 & 2000 & $\mathrm{ppm}$ \\
\hline 6 & Nitrogen dioxide & $\mathrm{NO}_{2}$ & $10102-44-0$ & 100 & 200 & 500 & $\mathrm{ppm}$ \\
\hline 7 & Sulfur dioxide & $\mathrm{SO}_{2}$ & $7446-09-5$ & 30 & 100 & 2000 & $\mathrm{ppm}$ \\
\hline 8 & Ammonia & $\mathrm{NH}_{3}$ & $7664-41-7$ & 20 & 50 & 500 & $\mathrm{ppm}$ \\
\hline 9 & Hydrogen chloride & $\mathrm{HCl}$ & $7647-01-0$ & 10 & 50 & 500 & $\mathrm{ppm}$ \\
\hline 10 & Hydrogen fluoride & $\mathrm{HF}$ & $7664-39-3$ & 3 & 10 & 100 & $\mathrm{ppm}$ \\
\hline 11 & Methane & $\mathrm{CH}_{4}$ & $74-82-8$ & 20 & 100 & 1000 & $\mathrm{ppm}$ \\
\hline 12 & Ethane & $\mathrm{C}_{2} \mathrm{H}_{6}$ & $74-84-0$ & * & & 200 & $\mathrm{ppm}$ \\
\hline 13 & Ethylene (Ethene) & $\mathrm{C}_{2} \mathrm{H}_{4}$ & $74-85-1$ & * & & 200 & $\mathrm{ppm}$ \\
\hline 14 & $n$-Propane & $\mathrm{C}_{3} \mathrm{H}_{8}$ & $74-98-6$ & * & & 200 & $\mathrm{ppm}$ \\
\hline 15 & $n$-Hexane & $\mathrm{C}_{6} \mathrm{H}_{14}$ & $110-54-3$ & * & & 200 & $\mathrm{ppm}$ \\
\hline 16 & Formaldehyde & $\mathrm{HCOH}$ & $50-00-0$ & 15 & & 70 & $\mathrm{ppm}$ \\
\hline
\end{tabular}

* The CEM hydrocarbon ranges depend on the application. Higher ranges and additional compounds are available upon request from Gasmet Technologies Oy. Note: Standard GAS-APP-003 application package includes one range per compound

FIGURE 2: Example of FTIR "library" for CEMS applications into MSW incenerators. 